Open Access

\title{
Long-Term Outcome of Endoscopic Papillary Large Balloon Dilatation
}

\author{
Chang-II Kwon \\ Digestive Disease Center, CHA Bundang Medical Center, CHA University, Seongnam, Korea
}

See "Late Complications and Stone Recurrence Rates after Bile Duct Stone Removal by Endoscopic Sphincterotomy and Large Balloon Dilation Are Similar to Those after Endoscopic Sphincterotomy Alone" by Ka Young Kim, Jimin Han, Ho Gak Kim, et al., on page 637-642

Since endoscopic papillary large balloon dilatation (EPLBD) was first introduced by Ersoz et al. ${ }^{1}$ in 2003, a lot of studies have reported a good therapeutic effect of EPLBD for the removal of difficult common bile duct (CBD) stones. Most of these studies evaluated a success rate of EPLBD compared with the existing endoscopic sphincterotomy (EST) or acute complications of EPLBD in terms of overcoming the burden of the procedure itself. ${ }^{2}$ With a success rate as high as $94 \%$ to $100 \%$ and a complication rate as low as $0 \%$ to $17 \%$, EPLBD has become an easier and safer modality for managing difficult stones. ${ }^{3}$ No guideline has yet been established for the application of EPLBD, and issues have recently emerged regarding the selection of appropriate patients and how to minimize complications. Lack of sufficient data on long-term outcome also calls for a large prospective study on the long-term effectiveness of EPLBD.

According to a recently published meta-analysis, EPLBD was found to achieve an overall successful clearance of bile duct stones, stone clearance at the first endoscopic retrograde cholangiopancreatography session, and removal of large stones, comparable with those achieved via EST. Based on the relatively low frequency of requiring mechanical lithotripsy and low rate of complications such as hemorrhage, the authors concluded that EPLBD can be considered for the removal of difficult common bile stones in patients with underlying coag-

\footnotetext{
Received: October 17, 2013 Revised: October 21, 2013

Accepted: October 22, 2013

Correspondence: Chang-Il Kwon

Digestive Disease Center, CHA Bundang Medical Center, CHA University, 59

Yatap-ro, Bundang-gu, Seongnam 463-712, Korea

Tel: +82-31-780-5641, Fax: +82-31-780-5219, E-mail: endoscopy@cha.ac.kr

(c) This is an Open Access article distributed under the terms of the Creative Commons Attribution Non-Commercial License (http://creativecommons.org/ licenses/by-nc/3.0) which permits unrestricted non-commercial use, distribution, and reproduction in any medium, provided the original work is properly cited.
}

ulopathy or requiring anticoagulation therapy. ${ }^{4-6}$

What are the long-term complications of EPLBD? Most of the published studies investigated stone recurrence, and studies on other late complications are either lacking or unknown. In a recent study about the long-term outcome of EPBD, cholangitis and cholecystitis were reported in $0.8 \%$ and $3.4 \%$ of patients, respectively, over a mean follow-up period of 4.4 years. ${ }^{7}$ In an issue of Clinical Endoscopy, Kim et al. ${ }^{8}$ reported that no difference in late complication rates of recurrent cholangitis and cholecystitis was observed between to the EPLBD and EST groups (5.9\% and 3.3\%; $p=1.000)$.

Before I have mentioning on a stone recurrence which is most common long term complication after EPLBD, I will make a short comment for a stone recurrence. The reported stone recurrence rate after CBD stone removal is approximately $4 \%$ to $24 \%$, and various factors, including older age, periampullary diverticulum, gallbladder stone, angulated CBD, mechanical lithotripsy, and severe bile duct dilatation, are known to affect stone recurrence. ${ }^{9-13}$ Compared with endoscopic papillary balloon dilatation (EPBD), which retains sphincter function to a certain degree, EPLBD has been speculated to have a greater effect on stone recurrence because it dilates the biliary orifice to a much greater extent. EPLBD may completely destroy the functionality of the sphincter of Oddi, although no observational study has provided data to support this. Due to this, the pressure gradient between the CBD and duodenum is removed, resulting in frequent occurrence of subsequent duodenobiliary reflux, hence the hypothesis that EPLBD will cause additional complications during the long term. ${ }^{3}$

EPBD has been reported to be associated with a lower rate of recurrent bile duct stones for long-term outcome compared with EST. After a median follow-up of 6.7 years in a previous study, the overall biliary complication rate was $10.1 \%$ in the 
EPBD group, compared to $25.0 \%$ in the EST group. Meanwhile, the stone recurrence rates were $8.0 \%$ and $17.4 \%$ in the EPBD and EST groups, respectively, indicating a statistically significant difference between both groups. ${ }^{14}$ The authors implicated additional late complications caused by biliary sphincter dysfunction from EST during the long-term follow-up period as a cause of this difference. Papillary functions were confirmed to be preserved in $70 \%$ of the patients after EPBD. $^{15}$

Considering the impossibility of preserving papillary function with EPLBD, stone recurrence after EPLBD is speculated to be higher than that after EPBD or comparable with that after EST; few studies have been published on this issue, but reports so far state that EPLBD itself does not increase stone recurrence. ${ }^{16,17}$ In an issue of Clinical Endoscopy and in contrast to previous reports, Kim et al. ${ }^{8}$ reported a comparable or lower rate of posttreatment bile duct stone recurrence (6.9\%) when comparing EPLBD with EST, albeit without significant differences. The results suggested that unlike in EST, previously known factors rather than EPLBD itself were associated with the increased stone recurrence rate. The finding of this study is significant in that it can be cited as evidence of the long-term safety of EPLBD.

EPLBD was first introduced as a modality for a more comfortable removal of difficult CBD stones. Since its introduction, a number of early studies have been conducted and reported to clarify the issue that EPLBD might increase the risk for serious adverse events such as acute pancreatitis and perforation, compared with EST. Over the past 10 years, the technical methods and safety of EPLBD have been established and the indication has been expanded. Development of guidelines for the application of EPLBD has been an ongoing effort to minimize the occurrence of any potential serious adverse events and to allow for a safer procedure by analyzing the fundamental causes of such serious adverse events. In addition to such efforts, 10 years after the introduction of EPLBD, more studies on long-term safety of EPLBD, as those reported in this issue, are necessary. Hopefully, with the accumulated evidence of positive effects from the increasing number of previous and ongoing studies investigating the outcomes of EPLBD, the modality would be recognized worldwide as a safe and important therapy in the field of ERCP.

\section{Conflicts of Interest}

The author has no financial conflicts of interest.

\section{REFERENCES}

1. Ersoz G, Tekesin O, Ozutemiz AO, Gunsar F. Biliary sphincterotomy plus dilation with a large balloon for bile duct stones that are difficult to extract. Gastrointest Endosc 2003;57:156-159.

2. Lee DK, Han JW. Endoscopic papillary large balloon dilation: guidelines for pursuing zero mortality. Clin Endosc 2012;45:299-304.

3. Yasuda I, Itoi T. Recent advances in endoscopic management of difficult bile duct stones. Dig Endosc 2013;25:376-385.

4. Feng Y, Zhu H, Chen X, et al. Comparison of endoscopic papillary large balloon dilation and endoscopic sphincterotomy for retrieval of choledocholithiasis: a meta-analysis of randomized controlled trials. J Gastroenterol 2012;47:655-663.

5. Mummadi RR, Fukami N, Shah RJ, Brauer BC, Yen RD, Chen YK. Safety and efficacy of endoscopic sphincterotomy (ES) followed by endoscopic papillary large balloon dilation (EPLBD) for extraction of large common bile duct stones (LBDS): a systematic review and meta-analysis. Gastrointest Endosc 2010;71:AB161.

6. Madhoun MF, Wani S, Hong SK, Tierney WM, Maple JT. Endoscopic sphincterotomy (ES) combined with endoscopic papillary large balloon dilation (EPLBD) reduces the need for mechanical lithotripsy in patients with large bile duct stones: a systematic review and meta-analysis. Gastrointest Endosc 2012;75(4 Suppl):AB381.

7. Tsujino T, Kawabe T, Komatsu Y, et al. Endoscopic papillary balloon dilation for bile duct stone: immediate and long-term outcomes in 1000 patients. Clin Gastroenterol Hepatol 2007;5:130-137.

8. Kim KY, Han J, Kim HG, et al. Late complications and stone recurrence rates after bile duct stone removal by endoscopic sphincterotomy and large balloon dilation are similar to those after endoscopic sphincterotomy alone. Clin Endosc 2013;46:637-642.

9. Keizman D, Shalom MI, Konikoff FM. An angulated common bile duct predisposes to recurrent symptomatic bile duct stones after endoscopic stone extraction. Surg Endosc 2006;20:1594-1599.

10. Ueno N, Ozawa Y, Aizawa T. Prognostic factors for recurrence of bile duct stones after endoscopic treatment by sphincter dilation. Gastrointest Endosc 2003;58:336-340.

11. Ando T, Tsuyuguchi T, Okugawa $\mathrm{T}$, et al. Risk factors for recurrent bile duct stones after endoscopic papillotomy. Gut 2003;52:116-121.

12. Kim DI, Kim MH, Lee SK, et al. Risk factors for recurrence of primary bile duct stones after endoscopic biliary sphincterotomy. Gastrointest Endosc 2001;54:42-48.

13. Cheon YK, Lehman GA. Identification of risk factors for stone recurrence after endoscopic treatment of bile duct stones. Eur J Gastroenterol Hepatol 2006;18:461-464.

14. Yasuda I, Fujita N, Maguchi H, et al. Long-term outcomes after endoscopic sphincterotomy versus endoscopic papillary balloon dilation for bile duct stones. Gastrointest Endosc 2010;72:1185-1191.

15. Kojima Y, Nakagawa H, Miyata A, et al. Long-term prognosis of bile duct stones: endoscopic papillary balloon dilatation versus endoscopic sphincterotomy. Dig Endosc 2010;22:21-24.

16. Kim KH, Rhu JH, Kim TN. Recurrence of bile duct stones after endoscopic papillary large balloon dilation combined with limited sphincterotomy: long-term follow-up study. Gut Liver 2012;6:107-112.

17. Ha DW, Song GA, Kim DU, et al. Recurrent common bile duct stone and endoscopic treatment after endoscopic papillary large balloon dilatation with minor endoscopic sphincterotomy. Korean J Gastroenterol 2011;57:352-357. 